\title{
Are conservatives overconfident?
}

\author{
Pietro Ortoleva ${ }^{\text {a }}$, Erik Snowberg ${ }^{b, c, *}$
}

\footnotetext{
a Department of Economics, Columbia University, New York, New York, United States.

b Division of the Humanities and Social Sciences, California Institute of Technology, Pasadena, California, United States of America.

${ }^{c}$ National Bureau of Economic Research, Cambridge, Massachusetts, United States of America.
}

\begin{abstract}
Recent studies suggest psychological differences between conservatives and liberals, including that conservatives are more overconfident. We use a behavioral political economy model to show that while this is undoubtedly true for election years in the current era, there is no reason to believe that conservative ideologies are intrinsically linked to overconfidence. Indeed, it appears that in 1980 and before, conservatives and liberals were equally overconfident.
\end{abstract}

JEL classifications: D03; D72; D83; C83

Keywords: Behavioral political economy; Overconfidence; Media; Ideology; Extremeness

*Corresponding author. E-mail: snowberg@caltech.edu. Tel: +1 617233 3389. Fax: None. 


\section{Introduction}

In recent years, there have been a number of scholarly articles written with the premise that there is something fundamentally different about conservatives and conservative beliefs. Alford et al. (2005) shows that there are genetic differences between liberals and conservatives. Oxley et al. (2008) shows that conservatives are more responsive to threatening stimuli. Jost et al. (2003) finds that conservatives are less prone to enduring uncertainty. This lead Moore and Healy (2007) to speculate, and find, that conservatives were, in their study, more overconfident.

Our own recent work seems to add to this general trend, finding that conservatives are more overconfident in a large, representative U.S. survey (Ortoleva and Snowberg, 2015). However, our work differs in a fundamental way from the work described above: the findings are based on a formal model of beliefs. In our model, the relationship between overconfidence and conservatism comes from a single parameter, $x$, that captures the average signal received by the members of the society in a given period, and specifically, from the fact that in our dataset $x>0$. But there is nothing in the model that says that this parameter has to be greater than zero. In fact, in other times and places it could be equal to zero, or less than zero, or vary over time, leading to much different results.

In this paper we generalize the model of Ortoleva and Snowberg (2015) to allow this parameter to vary over time, and investigate the implications of that generalization for the relationship between overconfidence and ideology (in Sections 2 and 4). This generalization introduces the concept of a political zeitgeist - a prevailing set of political beliefs in a period that shape people who live through that period. ${ }^{1}$

After the theoretical analysis, we turn to examine the predictions in data from a representative survey of the U.S. in 2011 (in Sections 3 and 5). This analysis benefits from the presence of two measures of overconfidence that we can use to eliminate biases due to measurement error. We find that, contrary to the analysis of similar data in 2010, there is no

\footnotetext{
${ }^{1}$ Zeitgeist is an English loan word from German, which the Oxford English Dictionary defines as, "The defining spirit or mood of a particular period of history as shown by the ideas and beliefs of the time."
} 
relationship between overconfidence and conservatism. From this, we conclude that $x=0$ in 2011, and show that other predictions of the model that depend on $x$ have changed in accordance with the change in $x$. That is, despite the change in the value of $x$, the theory continues to provide an accurate description of the data.

We then take advantage of the fact that our extended model allows $x$ to change over time - that is, there is a time dependent $x$, given by $x_{t}$, when examining the relationship between age, media exposure, and overconfidence in Section 6. Here, we find support for the more nuanced predictions of the theory. In particular, our analysis of media exposure once again is compatible with the conclusion that $x_{t}=0$ in our data. However, the patterns associated with age and ideology suggest that the residual effects of $x_{t-1}>0, x_{t-2}>0, \ldots$ in many previous years are still influencing older U.S. citizens today.

Our final set of analyses tries to confirm this using data from the American National Election Study's cumulative data file. This data contains many similar surveys going back over 50 years. However, we are hampered by the fact that key variables we wish to analyzeideology, media exposure, and overconfidence - are not consistently measured (or measured at all) during that entire time period. Still, we find evidence consistent with $x>0$ in election years from 1982-2008. However, before 1980, it appears that $x=0$ (or very close to it).

Bringing these results together, it appears that there is no intrinsic relationship between overconfidence and conservatism, yet our theory is still consistent with the data we have analyzed. In particular, there is little doubt that conservatives were more overconfident in 2010, the year of our previous study. Moreover, this is likely to have been the case in election years since 1980. However, before 1980, and in non-election years (when surveys are rarely run), conservatives and liberals appear to be equally overconfident. These results are consistent with our (fully formalized) theory, and provides a deeper understanding of political belief formation: it appears that these differences can be rationalized by the existence of different political zeitgeists that shape people's political beliefs over the course of their lives.

More generally, this suggests that in order to truly understand the links between different behavioral economic traits and biases and political attributes, it is necessary to build and 
test models which specify where these links come from. Failing to do so creates confusion when "things change", as they inevitably do. For example, Foley (2013) tries to replicate the study of Oxley et al. (2008), referenced above, and finds the opposite result: namely, that liberals are more sensitive to threatening stimuli. Because there is no formal theory underlying these results, there is no way to tell if the difference comes from a change in the conception of ideology, a change in the set of stimuli people are concerned about, or a change in the relationship between threatening stimuli and ideology, or more than one of these factors.

\section{Theoretical framework}

The basic structure of the theory follows Ortoleva and Snowberg (2015) with one important difference: we allow for shocks to the state variable. This allows us to examine time variation in preferences and overconfidence, giving a crisper picture of the relationship between overconfidence and left-right ideology: $\left.\right|^{2}$

For modeling purposes, we consider "today" to be period $T$. There is a unit measure of citizens $i \in[0,1]$, each with age $t_{i} \sim F_{t}$ with support $\{1,2,3, \ldots, T\}$. Each citizen $i$ has a utility over political actions that depends on a state of the world. A citizen's belief about the state are determined by her experiences, and her ideology reflects these beliefs.

Utilities: Each citizen $i$ has a standard quadratic-loss utility over actions $a_{i} \in \mathbb{R}$, which depends on a state $x \in \mathbb{R}$

$$
U\left(a_{i} \mid x\right)=-\left(a_{i}-x\right)^{2} .
$$

Throughout, $a_{i}$ is the policy implemented by government $H^{3}$ The state $x$ is a single draw from $\mathcal{N}[0, \tau]$ where $\tau$ is the precision of the normal distribution 4 Importantly, $x$ does not change

\footnotetext{
${ }^{2}$ Another difference from Ortoleva and Snowberg (2015) is that we omit preferences from ideology - that is, we have a common-value environment. All results would remain the same if we included preferences as well, but it would complicate the analysis without producing additional, testable results.

${ }^{3}$ To add preference biases, we could model $U\left(a_{i}, b_{i} \mid x\right)=-\left(a_{i}-p_{i}-x\right)^{2}$, where $p_{i} \sim \mathcal{N}\left[0, \tau_{p}\right]$.

${ }^{4}$ The precision is the inverse of the variance.
} 
over time, but aggregate beliefs about it may, as we detail below.

With uncertainty about the state, it is straightforward to show that the policy preferred by citizen $i$ will be $a_{i}^{*}=E_{i}[x]$, where $E_{i}$ is the expectation taken over citizen $i$ 's beliefs. We define this quantity as the citizen's ideology,

$$
\mathcal{I}_{i} \equiv E_{i}[x]
$$

and, as the expectation of $x$ is zero, ideological extremeness as $\mathcal{E}_{i}=\left|\mathcal{I}_{i}\right|$.

Experiences, Beliefs, and Correlational Neglect: The core of the model is the process by which citizens form beliefs about the state. Each citizen is well-calibrated about the informativeness of each individual experience (signal), but underestimates the correlation between signals.

Citizen $i$ has been alive for $t_{i} \in\{1,2,3, \ldots, T\}$ periods, which implies he was born in period $b_{i} \equiv T-t_{i}$. In each period a citizen $i$ is alive he receives $n_{i}$ signals. Citizen $i$ 's, $j$ th experience in period $t$ is determined by:

$$
e_{i j t}=x+\eta_{t}+\varepsilon_{i j t}
$$

where $\eta_{t}$ is an i.i.d. draw, once per period for the entire population, according to a $\mathcal{N}\left[0, \tau_{\eta}\right]$ mean-zero normal distribution with precision $\tau_{\eta}$. The random variable $\eta_{t}$ is the formal expression of a political zeitgeist as defined in Section $1-$ a prevailing set of political beliefs, in a period, that shape people who live through that period.

The presence of a zeitgeist is the major departure from our previous work. It means that there is "effectively" a new state $x_{t} \equiv x+\eta_{t}$ in each period, and that for citizens born in period $t$, all of their experiences will be centered around this state. However, as citizens age, their beliefs about $x$ will be determined by the sequence of zeitgeists the citizen lives through $5^{5}$

\footnotetext{
${ }^{5}$ The fact that zeitgeists are independent draws means that they will be uncorrelated across time. This is a happy medium between two contrasting perspectives: one that expects political culture to change slowly over time (implying a positive correlation), and another that sees current political attitudes as a reaction to past political attitudes (implying a negative correlation). Allowing for correlation between zeitgeists significantly complicates the analysis, however, all of our results should hold for relatively small correlations.
} 
Everything up until this point is common knowledge. Individual heterogeneity enters through the $\varepsilon_{i j t} \sim \mathcal{N}[0,1]$, and through differences in citizens' beliefs about the process generating that random variable. In particular, the $\varepsilon_{i j t}$ drawn for a given citizen are correlated with each other (but not correlated with the $\varepsilon_{i j t}$ of other citizens), with $\operatorname{Corr}\left[\varepsilon_{i j t}, \varepsilon_{i j^{\prime} t^{\prime}}\right]=\rho$. However, citizen $i$ underestimates this correlation: he believes $\operatorname{Corr}\left[\varepsilon_{i j t}, \varepsilon_{i j^{\prime} t^{\prime}}\right]=\rho_{i} \in[0, \rho) !^{6}$

Definition. A citizen suffers from correlational neglect when $\rho_{i}<\rho$.

The magnitude of correlational neglect varies by citizen, and is an i.i.d. draw from $F_{\rho_{i}}$ with support $[0, \rho)$, and $\rho_{i} \perp \mathbf{e}_{i}$. As $\rho_{i}<\rho$ for all $i$, all citizens in our model are correlational neglecters.

Overconfidence: As our data measures overconfidence, our theoretical results are in terms of this variable. Denote the precision of citizen $i$ 's posterior belief as $\kappa_{i}+\tau$, which we refer to as the citizen's confidence. Additionally, denote by $\kappa+\tau$ the posterior belief the citizen would have if she had accurate beliefs about the correlation between signals.

Definition. Overconfidence is the difference between a citizen's confidence, and how confident she would be if she were properly calibrated, $\kappa_{i}-\kappa$. Given two citizens $i$ and $j$, we say that $i$ is more overconfident than $j$ if $\kappa_{i} \geq \kappa_{j}>0$.

We often refer to $\kappa_{i}$ as a citizen's level of overconfidence.

\section{Data}

The data which we focus on for much of our paper comes from the Caltech module and the common content of the Cooperative Congressional Election Study (CCES) Alvarez, 2011,

We leave a full treatment of this question to future research.

${ }^{6}$ Formally, $\varepsilon_{i}$ is distributed according to a mean-zero multinomial normal with covariance matrix

$$
\Sigma_{\varepsilon_{i}}=\left(\begin{array}{cccc}
1 & \rho & \cdots & \rho \\
\rho & 1 & \cdots & \rho \\
\vdots & \vdots & \ddots & \vdots \\
\rho & \rho & \cdots & 1
\end{array}\right) \text {. However, citizen } i \text { believes that } \Sigma_{\varepsilon_{i}}=\left(\begin{array}{cccc}
1 & \rho_{i} & \cdots & \rho_{i} \\
\rho_{i} & 1 & \cdots & \rho_{i} \\
\vdots & \vdots & \ddots & \vdots \\
\rho_{i} & \rho_{i} & \cdots & 1
\end{array}\right) .
$$

Each $\varepsilon_{i j t}$ has unit variance, so $\operatorname{Corr}\left[\varepsilon_{i j t}, \varepsilon_{i j^{\prime} t^{\prime}}\right]=\operatorname{Cov}\left[\varepsilon_{i j t}, \varepsilon_{i j^{\prime} t^{\prime}}\right]=\rho$. We also assume that $\eta \perp \varepsilon_{i}$. 
Ansolabehere, 2011). The data in Section 7 comes from the American National Election Survey cumulative data file. As the ANES is relatively well known, we focus in this section on the CCES data, and describe any necessary details about the ANES data in Section 7.

As noted in Ortoleva and Snowberg (2015), the CCES is an annual cooperative survey. Participating institutions purchase a module of at least 1,000 respondents, who are asked 10-15 minutes of customized questions. In addition, every respondent across all modules is asked the same battery of basic economic and political questions. The complete survey is administered online by Knowledge Networks. Each module uses a matched-random sampling technique to achieve a representative sample, with over-sampling of certain groups Ansolabehere, 2012; Ansolabehere and Rivers, 2013). For empirical specifications which involve overconfidence, we use the Caltech module of 1,000 respondents. When a measure of overconfidence is not needed, we can use the entire CCES, which contains 20,150 respondents.

\subsection{Ideology and Extremeness}

The predictions in this paper are mostly concerned with ideological extremeness, but in some cases left-right ideology will be an important left-hand-side variable. Both are constructed using the same process.

The CCES twice asks respondents to report their ideology: from extremely liberal to extremely conservative. The first elicitation is when the respondent agrees to participate in surveys (on a five point scale), and the second when taking the survey (on a seven point scale). We normalize each of these measures to the interval $[-1,1]$, and average them. Those that report they "don't know" are treated as moderates (0).7

This measure of ideology is then folded around the median ideology, which happens to be exactly zero (moderate).

\footnotetext{
${ }^{7}$ This is exactly the preferred self-reported ideology measure in Ortoleva and Snowberg (2013).
} 


\subsection{Overconfidence}

The most important feature of this data, for our purposes, is that it allows for a measure of overconfidence. This measure is constructed in the same way as in Ortoleva and Snowberg (2015): from four questions about respondent confidence in their guesses about four factual quantities. This level of confidence is adjusted for a respondent's accuracy on the factual question, leaving the respondent's overconfidence. This is similar to the standard psychology measure in that it elicits confidence and controls for knowledge. However, it differs in that we cannot say for certain whether a given respondent is overconfident, just that their confidence, conditional on knowledge, is higher or lower than another respondent. Therefore, we use previous research, which shows that (almost) everyone exhibits over-precision (almost) all the time (Moore and Healy, 2007, 2008), to argue that this is a measure of overconfidence.

While the factual and confidence questions in Ortoleva and Snowberg (2015), which come from the 2010 CCES, were asked as part of another set of studies Ansolabehere et al., 2013, 2014), the 2011 CCES also contains our own battery of questions to generate a second measure of overconfidence. That is, in 2011, like 2010, respondents were asked their assessment of the current unemployment and inflation rates, and what the unemployment and inflation rates would be a year from the date of the survey. Respondents were then asked their confidence about their answer to each question on a qualitative, six-point scale. The same questions were used to construct the measure in much of Ortoleva and Snowberg (2015).

The 2011 CCES had additional questions which allowed us to calculate a second measure of overconfidence on "general knowledge" questions. In particular, respondents were asked about the year of the telephone's invention, the year of Shakespeare's birth, the percent of the U.S. population living in California, and the population of Spain (in millions). After each of these factual questions, respondents were asked what the percent chance was that their answer was within a certain interval of the correct answer. For example, each respondent was asked for the percent chance, from 0-100, that their answer for the year of the telephone's 
invention was within 25 years of the correct answer 8

Confidence, $\kappa_{i}$ reflects both knowledge and overconfidence, so subtracting knowledge from confidence leaves overconfidence, $\kappa_{i}-\kappa 9^{9}$ As in Ortoleva and Snowberg (2015), to subtract knowledge, we deduct points from a respondent's reported confidence based on his or her accuracy, and thus knowledge, on the corresponding factual question. This is implemented conservatively: we regress confidence on an arbitrary, fourth-order polynomial of accuracy, and use the residual as a measure of overconfidence. This allows the regression to pick the points to deduct for each level of accuracy, such that knowledge absorbs as much variation as possible.

Each of the resultant overconfidence measures are measured with error, as some respondents with little knowledge will randomly provide accurate answers. Thus, we use the first principal component of the four measures 10 Finally, to standardize regression coefficients, we divide by the standard deviation.

Table 1 shows that both measures are correlated with self-reported ideological extremeness, in keeping with the main prediction, and Table 9, of Ortoleva and Snowberg (2015). Moreover, the correlations between the two measures and extremeness are statistically identical, despite the fact that the correlation between the two measures is only 0.35 . We maintain the same general form of the specifications by clustering standard errors by age when appropriate, and estimate specifications using WLS and the supplied CCES sample weights Ansolabehere, 2012).

The final two columns examine the results of instrumenting the overconfidence measure in our previous work (based on questions about the economy) with the overconfidence measure derived from general knowledge questions. This, again, produces results consistent with

\footnotetext{
${ }^{8}$ Thus, we followed the standard practice in psychology of asking about confidence intervals, but our elicitation process would require us to invert these answers assuming a two parameter distribution-like the normal - to establish the confidence interval. The intervals in the questions were chosen by piloting our questions on Mechanical Turk, and then selecting an interval that was approximately one standard deviation of the answers given there. For more on using Mechanical Turk in survey research, see Berinsky et al. (2012).

${ }^{9}$ Theoretically, we need to control for the precision a citizen would have if they were properly calibrated. As we do not observe this, we control for accuracy, which is, in our theory, correlated.

${ }^{10}$ Consistent with each measure consisting of an underlying dimension plus i.i.d. measurement error, the first principal component weights each of the four questions approximately equally.
} 
Table 1: The relationship between overconfidence and extremeness is stronger when accounting for measurement error.

\begin{tabular}{|c|c|c|c|c|c|c|}
\hline Dependent Variable: & \multicolumn{6}{|c|}{ Ideological Extremeness } \\
\hline $\begin{array}{l}\text { Overconfidence } \\
\text { (Economy) }\end{array}$ & $\begin{array}{c}0.16^{* * *} \\
(.047)\end{array}$ & $\begin{array}{l}0.11^{* * *} \\
(.040)\end{array}$ & & & & \\
\hline $\begin{array}{l}\text { Overconfidence } \\
\text { (General Knowledge) }\end{array}$ & & & $\begin{array}{l}0.17^{* * *} \\
(.043)\end{array}$ & $\begin{array}{l}0.12^{* *} \\
(.050)\end{array}$ & & \\
\hline $\begin{array}{l}\text { Overconfidence } \\
\text { (Instrumented) }\end{array}$ & & & & & $\begin{array}{c}0.49^{* * *} \\
(.15)\end{array}$ & $\begin{array}{c}0.35^{* *} \\
(.15)\end{array}$ \\
\hline Economic Controls & & $\mathrm{Y}$ & & $\mathrm{Y}$ & & $\mathrm{Y}$ \\
\hline Number of Signals & & $\mathrm{Y}$ & & $\mathrm{Y}$ & & $\mathrm{Y}$ \\
\hline$R^{2}$ & 0.024 & 0.32 & 0.030 & 0.32 & 0.030 & 0.32 \\
\hline$N$ & \multicolumn{6}{|c|}{989} \\
\hline
\end{tabular}

Notes: ${ }^{* *},{ }^{* *},{ }^{*}$ denote statistical significance at the $1 \%, 5 \%$ and $10 \%$ level with standard errors, clustered by age (69 clusters), in parentheses. All specifications estimated using WLS with CCES sampling weights.

there being measurement error in our measure of overconfidence: the coefficient triples in the IV regressions: ${ }^{11}$ This implies that the relationships in Ortoleva and Snowberg (2015) are severely underestimating the importance of overconfidence in political beliefs. Given the importance of measurement error to our previous results, we will use IV specifications when estimating the effects of overconfidence.

\subsection{Number of Signals}

The model in Section 2 allows for more nuanced predictions about the role of signals in ideology and extremeness. Age - calculated as 2011 minus the year of a respondent's birthis the most natural proxy for $t_{i}$ the number of periods a citizen (respondent) has been alive. We proxy for $n_{i}$, the number of signals a citizen receives in a given period, by his media exposure. The CCES contains four questions that ask whether or not a respondent received news from a specific media channel: blogs, TV, radio, or newspapers. We take the first principal component of these four yes/no questions to create a more continuous index of

\footnotetext{
${ }^{11}$ Note that IV here is used to eliminate the attenuation bias associated with measurement error, not to make claims about causality. For a review of this approach to reducing attenuation bias, see Hausman (2001).
} 
media exposure. This principal component also de-emphasizes TV, as nearly all respondents report getting political information from this channel.

\subsection{Other Controls}

Political economy theories generally view ideology as a function of wealth or income. Therefore, we include controls for all the wealth and income related variables in the CCES. The CCES provides these controls as categories: for example, rather than providing years of education, it groups education into categories such as "Finished High School". Thus, we introduce a dummy variable for each category of each economic control. We also include a category for missing data for each variable. These controls are: income (18 categories), education (6 categories), stock ownership (3 categories), home ownership (3 categories), union

/ union member in household (8 categories), state (51 categories, including DC). These are the same controls used in Ortoleva and Snowberg (2015).

All controls are entered categorically. This strategy is both too conservative and not conservative enough: not conservative enough because there are likely other relevant unobserved factors, and too conservative, as entering these variables categorically allows the implied control function to be non-monotonic, as opposed to the theoretical monotonic relationship. Media and age are sometimes used as controls, rather than independent variables of interest. There are 16 categories of media exposure. For age, there are 69 categories (years) when using the Caltech module, and 77 categories when using the entire CCES.

\section{Theoretical analysis}

This section shows how to map the more complicated model above - in which citizens receive multiple signals with a complex correlational structure - into a simpler model where each citizen receives only a single signal. In addition to making the model much more intuitive, this mapping also allows us to directly apply many of the results from our previous work.

Consider a model in which, as before, citizens have the same prior over $x \sim \mathcal{N}[0, \tau]$. 
However, now they only receive a single signal distributed $e_{i} \sim \mathcal{N}[x, \kappa], \forall i$, but citizens overestimate the precision of this signal: that is, they believe that $e_{i} \sim \mathcal{N}\left[x, \kappa_{i}\right]$, where $\kappa_{i} \geq \kappa$. If we properly define $e_{i}, \kappa$ and $\kappa_{i}$, then this "model" will give the same results.

\section{Proposition 1.}

Define $e_{i} \equiv \frac{1}{t_{i} n_{i}} \sum_{t=b_{i}}^{T} \sum_{j=1}^{n_{i}} e_{i j t}$. Then $\kappa=\frac{t_{i} n_{i}}{1+n_{i} \tau_{\eta}+\left(t_{i} n_{i}-1\right) \rho}$, and $\kappa_{i}=\frac{t_{i} n_{i}}{1+n_{i} \tau_{\eta}+\left(t_{i} n_{i}-1\right) \rho_{i}}$.

Proof. All proofs can be found in the Appendix.

This equivalence between models simplifies the analysis in a number of ways. First, note that a citizen's posterior beliefs will be distributed according to a $\mathcal{N}\left[\frac{\kappa_{i} e_{i}}{\kappa_{i}+\tau}, \kappa_{i}+\tau\right]$. In this formulation, it is apparent that both extremity of beliefs - the term that multiplies $e_{i}$-is increasing in overconfidence, $\kappa_{i}$. This is the main result in Ortoleva and Snowberg (2015), which is shown in Table 1.

More importantly for the purposes of this paper are the insights that can be gained by examining $e_{i}$. Recalling that $x_{t}=x+\eta_{t}$, note that

$$
E\left[e_{i}\right]=x+\frac{1}{t_{i}} \sum_{t=b_{i}}^{T} \eta_{t}=\frac{1}{t_{i}} \sum_{t=b_{i}}^{T} x_{t} \equiv \bar{x}_{t} .
$$

That is, $\bar{x}_{t}$-the average belief about $x$ in the population of citizens of age $t$-will depend both on $x$ and the various zeitgeists through which those citizens have lived. Moreover, because one additional signal will move the average belief much less when a citizen has observed many signals than when they have viewed very few, older citizens' beliefs, and thus ideology, should be much more stable than younger citizens. Both of these observations comport well with general stylized facts about ideology over one's lifetime (see, for example, Ghitza and Gelman, 2014).

In addition, our structured model allows us to make further, more nuanced, predictions that we can then analyze.

\section{Proposition 2.}


1. Ideology is increasing in overconfidence, $\frac{d E\left[\mathcal{I}_{i} \mid \kappa_{i}-\kappa\right]}{d\left(\kappa_{i}-\kappa\right)}>0$, if and only if $x>0$, and decreasing in overconfidence iff $x<0$.

2. If $x>0$ then $\operatorname{Cov}\left[\mathcal{E}, \kappa_{i} \mid \mathcal{I}_{i} \geq 0\right]>\operatorname{Cov}\left[\mathcal{E}, \kappa_{i} \mid \mathcal{I}_{i} \leq 0\right]$. If $x=0$ then $\operatorname{Cov}\left[\mathcal{E}, \kappa_{i} \mid \mathcal{I}_{i} \geq 0\right]=$ $\operatorname{Cov}\left[\mathcal{E}, \kappa_{i} \mid \mathcal{I}_{i} \leq 0\right]$.

\section{Proposition 3.}

1. Overconfidence, $\kappa_{i}$, is increasing in media exposure $n_{i}$ and age $t_{i}$.

2. The mean ideology in the population, conditional on $n, E\left[\mathcal{I}_{i} \mid\left(t_{i}, n_{i}\right)\right]$, is increasing in $\left(t_{i}, n_{i}\right)$ if and only if $x>0$, and decreasing in $\left(t_{i}, n_{i}\right)$ iff $x<0$.

3. If $x>0$ then $\operatorname{Cov}\left[\mathcal{E},\left(t_{i}, n_{i}\right) \mid \mathcal{I}_{i} \geq 0\right]>\operatorname{Cov}\left[\mathcal{E},\left(t_{i}, n_{i}\right) \mid \mathcal{I}_{i} \leq 0\right]$. If $x=0$ then $\operatorname{Cov}\left[\mathcal{E},\left(t_{i}, n_{i}\right) \mid \mathcal{I}_{i} \geq\right.$ $0]=\operatorname{Cov}\left[\mathcal{E},\left(t_{i}, n_{i}\right) \mid \mathcal{I}_{i} \leq 0\right]$.

These propositions come from Propositions 1, 4, 5, and 6 of Ortoleva and Snowberg (2015), and can be applied directly with a small, additional, assumption: $\tau_{\eta}$ needs to be small enough that increases in the variance of ideology as people age will swamp changes in the zeitgeist ${ }^{12}$ However, note that both of the above propositions depend on $x$, not $\bar{x}_{t}$. This choice is for generality. In particular, $\bar{x}_{t}$ will change over time, and will impact differently people of different ages. The propositions will continue to hold even with a distribution of ages (and thus, $\bar{x}_{t} \mathrm{~s}$ ) in the population as long as $\tau_{\eta}$ is small enough, and more subtle analyses are possible by allowing $\bar{x}_{t}$ to change. We will note these in the text as we analyze the data in the next two sections.

\section{Empirical analysis: Overconfidence}

With the theoretical structure in place, we can examine the propositions above in data. We start by examining Proposition 2 on the subset of the 2011 CCES data for which we have overconfidence measures. The first column of Table 2 shows that, according to the first part of Proposition 2, $x=0$. More prosaically, it shows that contrary to the analysis of 2010 survey data conducted in Ortoleva and Snowberg (2015) conservatives are not more

\footnotetext{
${ }^{12}$ The case when $x=0$ is not discussed in Ortoleva and Snowberg (2015), and, as such, is proved in the Appendix.
} 
Table 2: Patterns in overconfidence and ideology are consistent with theory, inconsistent with previous work.

\begin{tabular}{|c|c|c|c|c|c|c|}
\hline \multirow{2}{*}{$\begin{array}{l}\text { Dep. Variable } \\
\text { Sample }\end{array}$} & \multirow[t]{2}{*}{ Ideology } & \multicolumn{2}{|c|}{ Extremeness } & \multirow[t]{2}{*}{ Ideology } & \multicolumn{2}{|c|}{ Extremeness } \\
\hline & & $\begin{array}{l}\text { Left of } \\
\text { Median }\end{array}$ & $\begin{array}{l}\text { Right of } \\
\text { Median }\end{array}$ & & $\begin{array}{l}\text { Left of } \\
\text { Median }\end{array}$ & $\begin{array}{l}\text { Right of } \\
\text { Median }\end{array}$ \\
\hline $\begin{array}{l}\text { Overconfidence } \\
\text { (Instrumented) }\end{array}$ & $\begin{array}{l}0.054 \\
(.11)\end{array}$ & $\begin{array}{c}0.51^{* * *} \\
(.17)\end{array}$ & $\begin{array}{c}0.46^{* * *} \\
(.16)\end{array}$ & $\begin{array}{l}-0.0095 \\
(.12)\end{array}$ & $\begin{array}{c}0.47^{* *} \\
(.19)\end{array}$ & $\begin{array}{l}0.30^{*} \\
(.18)\end{array}$ \\
\hline Difference & \multicolumn{3}{|c|}{$\begin{array}{l}0.050 \\
(.23)\end{array}$} & & \multicolumn{2}{|c|}{$\begin{array}{l}0.17 \\
(.26)\end{array}$} \\
\hline Economic Controls & & & & Y & Y & Y \\
\hline Media & & & & Y & Y & Y \\
\hline Age & & & & Y & Y & Y \\
\hline$R^{2}$ & 0.098 & & & 0.29 & & \\
\hline $\mathrm{N}$ & 989 & 572 & 669 & 989 & 572 & 669 \\
\hline
\end{tabular}

Notes: ${ }^{* * *},{ }^{* *},{ }^{*}$ denote statistical significance at the $1 \%, 5 \%$ and $10 \%$ level with standard errors, clustered by age (69 clusters), in parentheses. All specifications estimated using WLS with CCES sampling weights. Sample sizes for left and right add to more than the total sample as the median ideology (0) is included in both comparisons.

overconfident than liberals. The additional prediction in Proposition 2 - that the covariance between extremeness and overconfidence to the left and to the right of center should be the same as $x=0$ - is consistent with the data.

A natural question is how can these results be compatible with the findings in our previous work? This can occur from the presence of the zeitgeist, which influences aggregate signals received by the society, and thus the difference between left and right. However, one might note that the standard errors in this table are quite large, especially when controls are added. As such, there may be some question as to whether the results are different, or whether they just appear different due to insufficient sample size. Therefore we turn to empirical predictions where we can lean on a much larger dataset: those predictions having to do with the number of signals a citizen receives. 
Table 3: Overconfidence is positively correlated with media exposure and age.

\begin{tabular}{lcccc}
\hline \hline Dependent Variable: & Media & Age & Media & Age \\
\hline Overconfidence & $0.42^{* * *}$ & $0.48^{* * *}$ & $0.23^{* * *}$ & $0.44^{* * *}$ \\
$\quad$ Instrumented) & $(.092)$ & $(.10)$ & $(.10)$ & $(.11)$ \\
Economic Controls & & & $\mathrm{Y}$ & $\mathrm{Y}$ \\
$R^{2}$ & Not Defined & 0.28 & 0.20 \\
$\mathrm{~N}$ & & & 989 & \\
\hline \hline
\end{tabular}

Notes: ${ }^{* * *},{ }^{* *},{ }^{*}$ denote statistical significance at the $1 \%, 5 \%$ and $10 \%$ level with standard errors in parentheses. All specifications estimated using WLS with CCES sampling weights.

\section{Empirical analysis: Signals}

The first result regarding the number of signals, the first part of Proposition 3, is a bridge between overconfidence and the number of signals: it says that overconfidence is increasing in the number of signals. We test this proposition in Table 3. In order to use the instrumented measure of overconfidence, we enter overconfidence as the dependent variable in the regressions. While this may seem odd, as all the proposition predicts is a positive correlation, it is a perfectly legitimate way to look for such a correlation. ${ }^{13}$ The results here confirm the prediction, older citizens, and those with greater media exposure, are more overconfident.

We now move to examine the second and third parts of Proposition 3 using $n_{i}$, media exposure. The patterns here are the same as with overconfidence, except much more precise. In particular, $x$ is now a precisely estimated zero, and the difference between the covariances with extremeness to the right and to the left is extremely small.

The results for age upend things a bit: based on the regression of ideology on age, it would appear that $x>0$. However, this would be inconsistent with the result above for media exposure, where we found that $x=0$. How can the two be reconciled? The answer is subtle, and relies on the fact that age not only gives a citizen more signals, but also increases the number of periods, and thus zeitgeists, that a citizen lives through. Formally, recall that

\footnotetext{
${ }^{13}$ This can be shown formally using the Frisch-Waugh-Lovell Theorem.
} 
Table 4: Patterns in overconfidence and the number of signals make for a subtle application of the theory.

\begin{tabular}{|c|c|c|c|c|c|c|}
\hline \multirow{2}{*}{$\begin{array}{l}\text { Dep. Variable } \\
\text { Sample }\end{array}$} & \multirow[t]{2}{*}{ Ideology } & \multicolumn{2}{|c|}{ Extremeness } & \multirow[t]{2}{*}{ Ideology } & \multicolumn{2}{|c|}{ Extremeness } \\
\hline & & $\begin{array}{l}\text { Left of } \\
\text { Median }\end{array}$ & $\begin{array}{l}\text { Right of } \\
\text { Median }\end{array}$ & & $\begin{array}{l}\text { Left of } \\
\text { Median }\end{array}$ & $\begin{array}{l}\text { Right of } \\
\text { Median }\end{array}$ \\
\hline $\begin{array}{l}\text { Media Index } \\
\text { (Standardized) }\end{array}$ & $\begin{array}{c}-0.010 \\
(.11)\end{array}$ & $\begin{array}{c}0.12^{* * *} \\
(.011)\end{array}$ & $\begin{array}{c}0.098^{* * *} \\
(.014)\end{array}$ & & & \\
\hline $\begin{array}{l}\text { Age } \\
\text { (Standardized) }\end{array}$ & & & & $\begin{array}{c}0.088^{* * *} \\
(.012)\end{array}$ & $\begin{array}{c}-0.055^{* * *} \\
(.013)\end{array}$ & $\begin{array}{c}0.059^{* * *} \\
(.016)\end{array}$ \\
\hline Difference & & \multicolumn{2}{|c|}{$\begin{array}{l}0.018 \\
(.017)\end{array}$} & & \multicolumn{2}{|c|}{$\begin{array}{c}0.11^{* * *} \\
(.020)\end{array}$} \\
\hline Economic Controls & $\mathrm{Y}$ & $\mathrm{Y}$ & $\mathrm{Y}$ & & & \\
\hline Media Controls & & & & Y & Y & Y \\
\hline Age Controls & $\mathrm{Y}$ & Y & Y & Y & Y & Y \\
\hline$R^{2}$ & 0.069 & & & 0.075 & & \\
\hline $\mathrm{N}$ & 20,083 & 11,239 & 13,578 & 20,083 & 11,239 & 13,578 \\
\hline
\end{tabular}

Notes: ${ }^{* * *},{ }^{* *},{ }^{*}$ denote statistical significance at the $1 \%, 5 \%$ and $10 \%$ level with standard errors, clustered by age (77 clusters), in parentheses. All specifications estimated using WLS with CCES sampling weights. Sample sizes for left and right add to more than the total sample as the median ideology (0) is included in both comparisons.

$\bar{x}_{t}=x+\frac{1}{t_{i}} \sum_{t=b_{i}}^{T} \eta_{t}$, so $\bar{x}_{t}$ could be, on average, increasing with age. On the other hand, because a given level of media exposure will have people from all age groups in it, the average $E\left[\bar{x}_{t} \mid n\right]$ can be zero everywhere ${ }^{14}$

We can attempt to "back-out" the level of these $x_{t} \mathrm{~s}$ by examining people of different ages, and how their ideology changes with signals. To do so, we divide our data into four quartiles by age. Examining how ideology changes with media exposure for the youngest quartile will give a clean measure of $x_{t}$ for the current era, but backing out the full sequence of $x_{t}$ over time will be more difficult as it is not clear how to relatively weight the signals received from aging versus media exposure ${ }^{15}$

Taking these caveats into account, the results in Table 5 are somewhat consistent with the

\footnotetext{
${ }^{14}$ Note that we also control for age in the regressions where media is the independent variable of interest, although these controls have little effect on the results.

${ }^{15}$ Moreover, the distinction between age quartiles is done based on the dataset, and does not try to match the cutoffs between these groups to other signs of a shift in the political zeitgeist.
} 
Table 5: Analysis by quartile allows for some inferences about $x_{t}$ over time.

\begin{tabular}{lcccc}
\hline \hline \multirow{2}{*}{$\begin{array}{l}\text { Dependent Variable: } \\
\text { Quartile of Age: }\end{array}$} & Youngest & 2nd Youngest & 2nd Oldest & Oldest \\
\hline Media & $-0.076^{* * *}$ & 0.017 & 0.012 & $0.024^{*}$ \\
& $(.017)$ & $(.019)$ & $(.013)$ & $(.014)$ \\
Economic Controls & $\mathrm{Y}$ & $\mathrm{Y}$ & $\mathrm{Y}$ & $\mathrm{Y}$ \\
$R^{2}$ & 0.085 & 0.073 & 0.065 & 0.068 \\
\hline Age & -0.018 & $0.33^{* * *}$ & -0.022 & $0.17^{* * *}$ \\
& $(.084)$ & $(.074)$ & $(.049)$ & $(.032)$ \\
Economic Controls & $\mathrm{Y}$ & $\mathrm{Y}$ & $\mathrm{Y}$ & $\mathrm{Y}$ \\
$R^{2}$ & 0.079 & 0.078 & 0.065 & 0.072 \\
$N$ & 3,412 & 3,338 & 7,440 & 5,893 \\
\hline \hline
\end{tabular}

Notes: ${ }^{* * *},{ }^{* *},{ }^{*}$ denote statistical significance at the $1 \%, 5 \%$ and $10 \%$ with standard errors in parentheses. All specifications estimated using WLS with CCES sampling weights. Unequal quartile sizes come from the use of sampling weights.

patterns described above: $x_{t}$ seems to be negative today, but in the past was likely positive. This is especially true for the oldest quartile of respondents, whose past experience must be sufficiently positive to outweigh the negative $x_{t}$ in the current period. What is clearer is that $\bar{x}_{t}$ is increasing, and on average positive, when considering age.

\section{Empirical analysis: Historical data}

The final analysis we consider combines those in Section 5 and Section 6 by examining the patterns of overconfidence in historical data. As the data we have examined to this point are the only we are aware of that provide both good measures of political ideology and of overconfidence, we turn to a survey with greater coverage over time, but more limited measures of ideology and media exposure, and only a proxy for overconfidence: the American National Election Study (ANES). This survey is conducted in every U.S. Congressional or Presidential election year, that is, in every even-numbered year.

In particular, we follow a strategy based on the fact that many studies over time have found men to be more overconfident than women and use male as a proxy for "more over- 


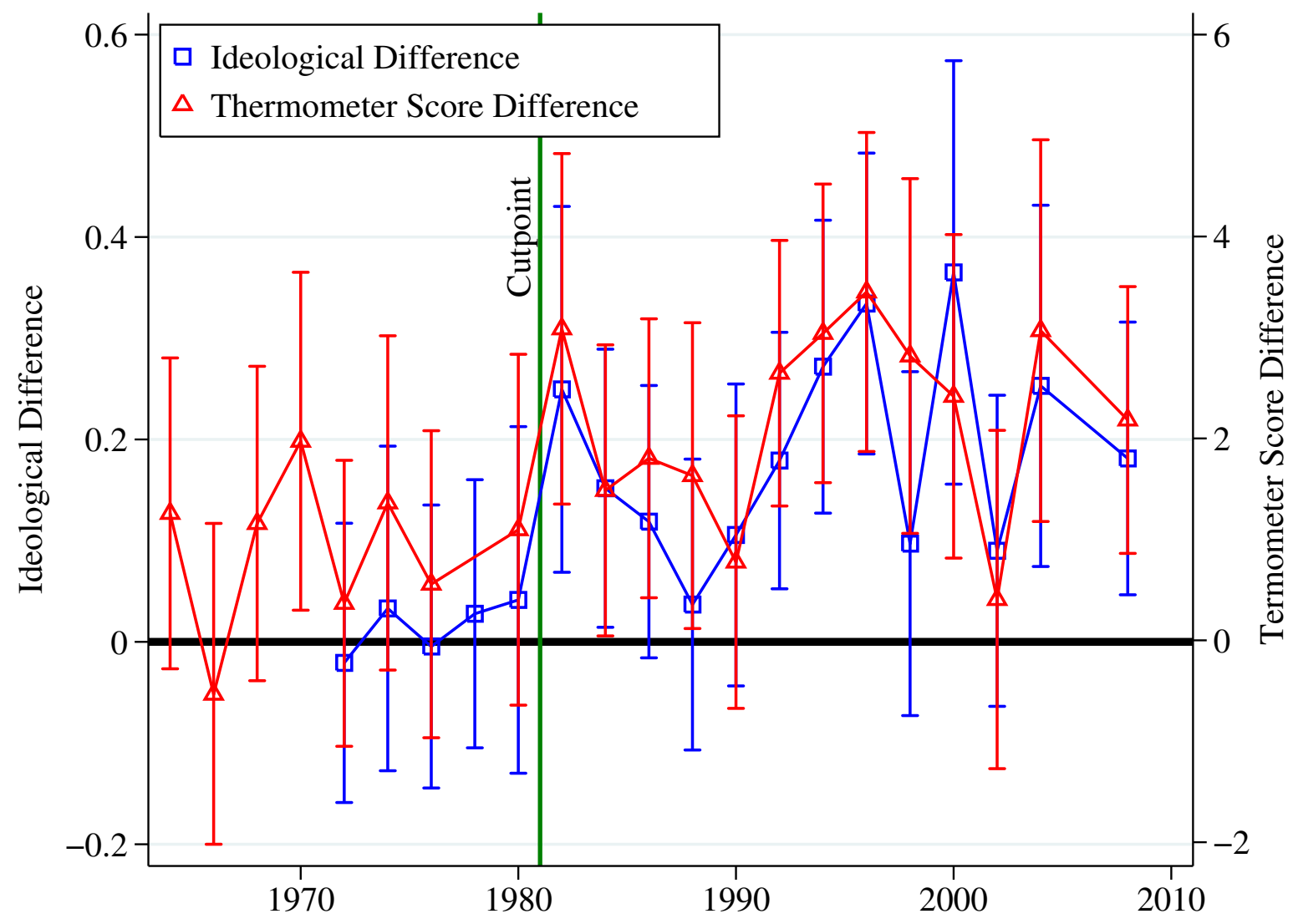

Figure 1: Men became significantly more conservative after 1980.

Note: Thermometer scores were not collected in 1978. There was no panel survey in 2006.

confident" ${ }^{16}$ For ideology we use two measures. The first is a self-reported ideology measure similar to that used in previous sections. The second asks respondents to give their impression of liberal and conservative ideologies on a "feelings thermometer" that goes from 0 to 100 (with 0 being "cold" or disagreement, and 100 indicating "hot" or complete agreement). The difference between these two feelings thermometers can be interpreted as a measure of ideology, and indeed, many studies do so (see, for example, Green, 1988, and citations therein).

We investigate if there is variation over time in the difference between the average ideology of men and women. Figure 1 plots the difference between men and women on both of these

\footnotetext{
${ }^{16}$ For example, Barber and Odean (2001) uses male as an instrument for overconfidence in a study of financial risk taking.
} 
scales over time with $95 \%$ confidence intervals in each year we have data. There is a clear rightward shift for men between 1980 and 1982. We divide the sample into two parts around 1981, and, in Table 6, we conduct a similar analysis to the one in Table 2.

Table 6: Data from the ANES is broadly consistent with Proposition 2.

\begin{tabular}{|c|c|c|c|c|c|c|}
\hline Time Frame & \multicolumn{3}{|c|}{ Up to 1980} & \multicolumn{3}{|c|}{1982 and After } \\
\hline Dep. Variable & \multirow[t]{2}{*}{ Ideology } & \multicolumn{2}{|c|}{ Extremeness } & \multirow[t]{2}{*}{ Ideology } & \multicolumn{2}{|c|}{ Extremeness } \\
\hline Sample & & $\begin{array}{l}\text { Left of } \\
n\end{array}$ & $\begin{array}{l}\text { Right of } \\
\text { Median }\end{array}$ & & $\begin{array}{l}\text { Left of } \\
\text { Median }\end{array}$ & $\begin{array}{l}\text { Right of } \\
\text { Median }\end{array}$ \\
\hline \multicolumn{7}{|c|}{ Panel A: Self-Reported Ideology } \\
\hline Male & $\begin{array}{l}0.013 \\
(.032)\end{array}$ & $\begin{array}{c}0.14^{* * *} \\
(.027)\end{array}$ & $\begin{array}{c}0.10^{* * *} \\
(.025)\end{array}$ & $\begin{array}{c}0.18^{* * *} \\
(.022)\end{array}$ & $\begin{array}{c}0.012^{* *} \\
(.018)\end{array}$ & $\begin{array}{c}0.13^{* * *} \\
(.017)\end{array}$ \\
\hline Difference & \multicolumn{4}{|c|}{$\begin{array}{l}0.035 \\
(.037)\end{array}$} & \multicolumn{2}{|c|}{$\begin{array}{c}0.12^{* * *} \\
(.025)\end{array}$} \\
\hline Year Fixed Effects & $\mathrm{Y}$ & $\mathrm{Y}$ & $\mathrm{Y}$ & $\mathrm{Y}$ & $\mathrm{Y}$ & $\mathrm{Y}$ \\
\hline$N$ & 6,880 & 4,241 & 5,132 & 16,862 & 9,821 & 12,593 \\
\hline \multicolumn{7}{|c|}{ Panel B: Thermometer Scores } \\
\hline Male & $\begin{array}{c}0.88^{* * *} \\
(.28)\end{array}$ & $\begin{array}{c}0.72^{* * *} \\
(.24)\end{array}$ & $\begin{array}{c}1.61^{* * *} \\
(.25)\end{array}$ & $\begin{array}{c}2.17^{* * *} \\
(.22)\end{array}$ & $\begin{array}{l}-0.15 \\
(.18)\end{array}$ & $\begin{array}{c}1.92^{* * *} \\
(.20)\end{array}$ \\
\hline Difference & \multicolumn{4}{|c|}{$\begin{array}{c}0.89^{* *} \\
(.35)\end{array}$} & \multicolumn{2}{|c|}{$\begin{array}{c}2.07^{* * *} \\
(.27)\end{array}$} \\
\hline Year Fixed Effects & $\mathrm{Y}$ & $\mathrm{Y}$ & $\mathrm{Y}$ & $\mathrm{Y}$ & $\mathrm{Y}$ & $\mathrm{Y}$ \\
\hline$N$ & 11,439 & 6,551 & 8,709 & 20,192 & 11,795 & 14,428 \\
\hline
\end{tabular}

Notes: ${ }^{* * *},{ }^{* *},{ }^{*}$ denote statistical significance at the $1 \%, 5 \%$ and $10 \%$ level with standard errors in parentheses. The $N$ of the split-sample regressions do not sum to the $N$ of the ideology regression due to the fact that those respondents with the median ideology are included in both regressions.

The results in Table 6 are broadly consistent with the patterns predicted by Proposition 2 . We find no statistical difference in average ideology between men and women before 1982, and men are equally more ideologically extreme, regardless of their ideological direction. After 1982, men are significantly further to the right than women on average, and being male is more correlated with extreme ideologies to the right than to the left. For the thermometer scores, the difference in correlation between right and left expands as the ideological difference 
between men and women increases.

This data is thus consistent with Proposition 2, and suggests that, for election years - the only years that the ANES was conducted - after 1980, $x_{t}>0$, and was equal to zero for 1980 and before. This could be consistent with the patterns in the second panel of Table 5 - there seems to be a flattening of the relationship between ideology and age for those in late-middle or old age - but the caveats about interpreting these results directly discussed in Section 6 still apply.17

\section{The importance of Non-Bayesian behavior}

Before turning to a comprehensive, integrated discussion of the results in this paper, we provide one final analysis. Given the nuances of our theory necessary to explain the data, it may be tempting to conclude that a simpler theory, perhaps a fully Bayesian one, could account for our findings. However, the data in Ortoleva and Snowberg (2015) shows that, at least in 2010, the variance of ideology is increasing in age. As this cannot be rationalized by any fully Bayesian model, it is central to our argument for a more behavioral model, and in particular the model extended here.

Given the centrality of the relationship between media exposure and extremeness in falsifying fully Bayesian alternatives, it is thus useful to show that this relationship is not just a flash in the pan. Figure 2 shows how the squared deviation of ideology evolves with media exposure - how, in the language of this paper, $\operatorname{Var}\left[\mathcal{I} \mid n_{i}\right]$ changes with $n_{i}$-in the ANES data. As the finding of increasing variance is robust, we believe this argues strongly for taking the approach we do, and working through the nuances imposed by the fact that the world changes over time.

\footnotetext{
${ }^{17}$ One could also examine the relationship between age and ideology, and age and media exposure. However, there is no variation in these relationships: older respondents are always more conservative, and the media measure does not start until well after 1980. The former fact suggests that there is a natural tendency for older citizens to be more conservative that is not accounted for in the theory. Doing so would call for distinguishing this "natural" rate of movement to the right with slower and faster rates of becoming more conservative in citizens as they age, and tying this to the variation in $x_{t}$. We leave this for future research.
} 


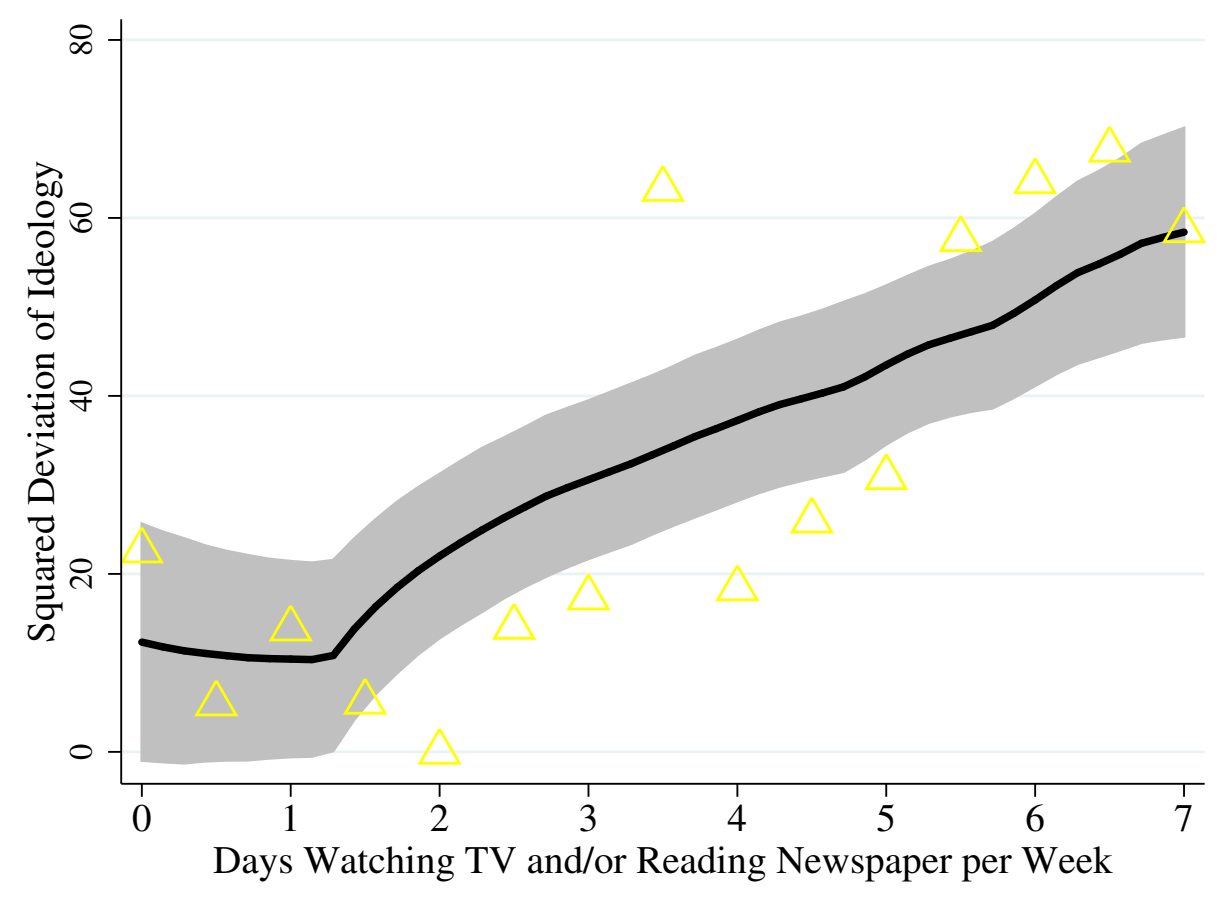

Figure 2: Media Exposure and Ideological Extremeness

Notes: Data from the ANES cumulative data file for 1984-2008, all years for which media measures are available. Each point is the average for a particular level of media exposure. Trendiness, in black, and $95 \%$ confidence intervals, in gray, use an Epanechnikov kernel with a bandwidth of 1 . Graph shows the relationship between residuals, controlling for year-by-income, year-by-education, and year-by-state fixed effects.

\section{Conclusion: Overconfidence and ideology}

The results in the previous sections suggest that there is no intrinsic relationship between overconfidence and conservatism, yet, our theory is still consistent with the data we have amassed. In particular, there is little doubt that conservatives were more overconfident in 2010, the year of our previous study. Moreover, this is likely to have been the case in election years since 1980. However, before 1980, and in non-election years (when surveys are rarely run), conservatives and liberals appear to be equally overconfident. These results are consistent with our (fully formalized) theory, and provide a deeper understanding of political belief formation: it appears that these differences can be rationalized by the existence of different political zeitgeists that shape people's political beliefs over the course of their lives. 
The difference between an election year, like 2010, and a non-election year, like 2011, is a bit more difficult to understand. Unfortunately, there are very few political surveys run in non-election years, on the presumption that there is very little political news at that point that citizens engage with. This may hold a clue to the results we see: as media will likely not contain nearly as much salient political news, it will appear that $x=0$ when considering signals through media, but longer-standing political beliefs, like those acquired through the experience of age, will persist. There is some evidence consistent with this in our data: the standard deviation of ideology in 2010 is 1.07, while in 2011 it is a much lower 0.86 . This implies that in election years people may be more attuned to political ideology, perhaps because of increased media coverage 18

One of the advantages of our approach is the fact that it relies on a well-specified mathematical theory, and, as such, can accumulate new insights into the formation of political beliefs. Indeed, the main insights we incorporate here are not all that new. First, the idea that different periods of history are dominated by different political ideas, or zeitgeists, is well-known. Second, it is known that the prevailing political beliefs when one first becomes politically active are of outsized importance in determining one's political orientation (Meredith, 2009; Mullainathan and Washington, 2009). While these insights may not be new, they have not been formalized, and by incorporating them into our theory about overconfidence we are able to produce new tests of these combined theories. These tests produce evidence consistent with the theory.19

An additional advantage of our correlational neglect model is that it can be embedded in

\footnotetext{
${ }^{18}$ To the extent that both of the shifts above represent a change in the zeitgeist (the former likely does, while further research will be necessary to confirm the latter), we can speculate about their causes. In 1980, Ronald Reagan was elected President of the U.S. This so called "Reagan Revolution" lead certain parts of the population to begin identifying as conservative, namely the "Reagan Democrats". The shift in 2011 is harder to speculate about, but it may be a result of the wild swings in public opinion - first towards the Tea Party in 2010, then back to President Obama in 2012 - that occurred in the wake of the financial crisis of 2008. It may also be due to the fact, as we suggest in the text, that political ideology is simply less important in non-election years.

${ }^{19}$ As with our previous work, we are only describing correlations in the data. However, the fact that these additional patterns are consistent with our theory increases the usefulness of it, as well as the chance that we have identified an important causal mechanism. For more on causation and threats to identification, see the conclusion of Ortoleva and Snowberg (2015).
} 
institutional models to determine how political behaviors affect outcomes. Indeed Levy and Razin (2015) shows the benefit of doing so: they show that correlational neglect can lead to better information aggregation in elections.

\section{Acknowledgements}

We thank Chee Kian Leong for his thought-provoking comments, and seminar attendees at the CESifo Conference on Behavioural Political Economy for their feedback. Snowberg gratefully acknowledges the support of NSF grant SES-1156154. 


\section{Appendix}

\section{Proposition 4.}

Define $e_{i} \equiv \frac{1}{t_{i} n_{i}} \sum_{t=b_{i}}^{T} \sum_{j=1}^{n_{i}} e_{i j t}$. Then $\kappa=\frac{t_{i} n_{i}}{1+n_{i} \tau_{\eta}+\left(t_{i} n_{i}-1\right) \rho}$, and $\kappa_{i}=\frac{t_{i} n_{i}}{1+n_{i} \tau_{\eta}+\left(t_{i} n_{i}-1\right) \rho_{i}}$.

Proof of Proposition 4: Recall that $e_{i j t}=x+\eta_{t}+\varepsilon_{i j t}$. As $\eta_{t} \perp \varepsilon_{i j t}$, we have that citizen $i$ believes

$$
\Sigma_{\mathbf{e}_{i}}=\Sigma_{\eta}+\Sigma_{\varepsilon_{i}}=\left(\begin{array}{cccc}
\mathbb{1} \tau_{\eta} & 0 & \cdots & 0 \\
0 & \mathbb{1} \tau_{\eta} & \cdots & 0 \\
\vdots & \vdots & \ddots & \vdots \\
0 & 0 & \cdots & \mathbb{1} \tau_{\eta}
\end{array}\right)+\left(\begin{array}{cccc}
1 & \rho_{i} & \cdots & \rho_{i} \\
\rho_{i} & 1 & \cdots & \rho_{i} \\
\vdots & \vdots & \ddots & \vdots \\
\rho_{i} & \rho_{i} & \cdots & 1
\end{array}\right)
$$

where $\Sigma_{y}$ is the covariance matrix of any random variable $y$, and $\mathbb{1}$ is an $n_{i} \times n_{i}$ matrix of 1s.

Thus, the posterior likelihood of citizen $i$ s beliefs is given by

$$
\begin{aligned}
& \mathcal{L}\left(x \mid \mathbf{e}_{i}\right) \quad \propto \quad \mathcal{L}\left(e_{i} \mid x\right) \mathcal{L}_{0}(x) \\
& \propto \exp \left\{-\frac{1}{2}\left(x-\mathbf{e}_{i}\right)^{T} \Sigma_{\mathbf{e}_{i}}^{-1}\left(x-\mathbf{e}_{i}\right)\right\} \exp \left\{-\frac{1}{2} x^{2} \tau\right\} \\
& =\exp \left\{-\frac{1}{2}\left(\begin{array}{c}
x-e_{i 11} \\
x-e_{i 21} \\
\vdots \\
x-e_{i n_{i} t_{i}}
\end{array}\right)^{T}\left(\tau_{\eta}\left(\begin{array}{cccc}
\mathbb{1} & 0 & \cdots & 0 \\
0 & \mathbb{1} & \cdots & 0 \\
\vdots & \vdots & \ddots & \vdots \\
0 & 0 & \cdots & \mathbb{1}
\end{array}\right)+\left(\begin{array}{cccc}
1 & \rho_{i} & \cdots & \rho_{i} \\
\rho_{i} & 1 & \cdots & \rho_{i} \\
\vdots & \vdots & \ddots & \vdots \\
\rho_{i} & \rho_{i} & \cdots & 1
\end{array}\right)\right)^{-1}\left(\begin{array}{c}
x-e_{i 11} \\
x-e_{i 21} \\
\vdots \\
x-e_{i n_{i} t_{i}}
\end{array}\right)\right\} \\
& * \exp \left\{-\frac{1}{2} x^{2} \tau\right\} \\
& =\exp \left\{-\frac{1}{2}\left(\frac{s_{i} x^{2}-2 x \sum_{j=1}^{n_{i}} \sum_{t=b_{i}}^{T} e_{i j t}}{1+n_{i} \tau_{\eta}+\left(s_{i}-1\right) \rho_{i}}+C\right)\right\} * \exp \left\{-\frac{1}{2} x^{2} \tau\right\} \\
& \propto \exp \left\{-\frac{1}{2} \frac{s_{i}+\tau\left(1+n_{i} \tau_{\eta}+\left(s_{i}-1\right) \rho_{i}\right)}{1+n_{i} \tau_{\eta}+\left(s_{i}-1\right) \rho_{i}}\left(x-\frac{s_{i} e_{i}}{s_{i}+\tau\left(1+n_{i} \tau_{\eta}+\left(s_{i}-1\right) \rho_{i}\right)}\right)^{2}\right\}
\end{aligned}
$$

where $C$ is constant with respect to $x, s_{i}=t_{i} \times n_{i}$, and from the definition in the statement of the proposition, $e_{i} \equiv \frac{1}{s_{i}} \sum_{j=1}^{n_{i}} \sum_{t=b_{i}}^{T} e_{i j t}$. Defining $D_{i} \equiv 1+n_{i} \tau_{\eta}+\left(s_{i}-1\right) \rho_{i}$, the posterior belief of a citizen is distributed according to 


$$
\mathcal{N}\left[\frac{s_{i} e_{i}}{s_{i}+D_{i} \tau}, \frac{s_{i}+D_{i} \tau}{D_{i}}\right]
$$

Substituting $s_{i}=D_{i} \kappa_{i}$ the posterior is given by $\mathcal{N}\left[\frac{\kappa_{i} e_{i}}{\kappa_{i}+\tau}, \kappa_{i}+\tau\right]$, which is the same as the posterior that a citizen would have if they received the single signal $e_{i}$, where the citizen believes $e_{i} \sim \mathcal{N}\left[x+\frac{1}{t_{i}} \sum_{t=b_{i}}^{T} \eta_{t}, \kappa_{i}\right]$. That is, $\kappa_{i}=s_{i} / D_{i}=\frac{t_{i} n_{i}}{1+n_{i} \tau_{\eta}+\left(t_{i} n_{i}-1\right) \rho_{i}}$, as desired. Finally, note that $E\left[e_{i}\right]=x+\frac{1}{t_{i}} \sum_{t=b_{i}}^{T} \eta_{t}$, and defining $\Sigma_{y}^{\left(k, k^{\prime}\right)}$ as the $\left(k, k^{\prime}\right)$ element of the covariance matrix of any random variable $y$

$$
\begin{aligned}
\operatorname{Var}\left[e_{i}\right] & =\left(\frac{1}{s_{i}}\right)^{2} \sum_{k=1}^{s_{i}} \sum_{k^{\prime}=1}^{s_{i}} \Sigma_{\mathbf{e}_{i}}^{\left(k, k^{\prime}\right)}=\left(\frac{1}{s_{i}}\right)^{2}\left(\sum_{k=1}^{s_{i}} \sum_{k^{\prime}=1}^{s_{i}} \Sigma_{\eta}^{\left(k, k^{\prime}\right)}+\sum_{k=1}^{s_{i}} \sum_{k^{\prime}=1}^{s_{i}} \Sigma_{\varepsilon_{i}}^{\left(k, k^{\prime}\right)}\right) \\
& =\left(\frac{1}{s_{i}}\right)^{2}\left(t_{i} n_{i}^{2} \tau_{\eta}+s_{i}+\left(s_{i}^{2}-s_{i}\right) \rho\right)=\frac{1+n_{i} \tau_{\eta}+\left(s_{i}-1\right) \rho}{s_{i}}
\end{aligned}
$$

Thus, $e_{i} \sim \mathcal{N}\left[x+\frac{1}{t_{i}} \sum_{t=b_{i}}^{T} \eta_{t}, \frac{t_{i} n_{i}}{1+n_{i} \tau_{\eta}+\left(t_{i} n_{i}-1\right) \rho}\right]$. Thus, the posterior precision of citizen $i$ should be $\frac{t_{i} n_{i}}{1+n_{i} \tau_{\eta}+\left(t_{i} n_{i}-1\right) \rho}+\tau=\kappa+\tau$, as desired.

Proof of Proposition 25: Consider two citizens with $\kappa_{1}>\kappa_{2}$. As $E\left[E_{i}[\mathcal{I} \mid \kappa]\right]=\frac{\kappa x}{\tau+\kappa}$, we have that $\frac{\kappa_{1} x}{\tau+\kappa_{1}}=\frac{\kappa_{2} x}{\tau+\kappa_{2}} \Longleftrightarrow x=0$. Thus, $\mathcal{I} \mid \kappa \sim \mathcal{N}\left[0, \frac{\tau_{b}(\tau+\kappa)^{2}}{\tau_{b} \kappa^{2}+(\tau+\kappa)^{2}}\right]$. As this is symmetric about zero for all $\kappa$, it implies $\operatorname{Cov}[E[\mathcal{E} \mid \kappa, \mathcal{I} \geq 0], \kappa]=\operatorname{Cov}[E[\mathcal{E} \mid \kappa, \mathcal{I} \leq 0], \kappa]$ and $\operatorname{Var}[\mathcal{I} \mid \mathcal{I} \geq 0]=\operatorname{Var}[\mathcal{I} \mid \mathcal{I} \leq 0]$. Finally, as this implies $f(\kappa \mid \mathcal{I} \geq 0)=f(\kappa \mid \mathcal{I} \leq 0)=f(\kappa)$, thus, $\operatorname{Var}[\kappa \mid \mathcal{I} \geq 0]=\operatorname{Var}[\kappa \mid \mathcal{I} \leq 0]$. Taken together this implies $\operatorname{Corr}[\mathcal{E}, \kappa \mid \mathcal{I} \geq 0]=$ $\operatorname{Corr}[\mathcal{E}, \kappa \mid \mathcal{I} \leq 0]$. 


\section{References}

Alford, J.R., Funk, C.L., Hibbing, J.R., 2005. Are political orientations genetically transmitted? American Political Science Review, 99, 153-167.

Alvarez, R.M., 2011. Cooperative congressional election study, 2011: Caltech content. [Computer File] Release 1: June 20, 2013. Pasadena, CA: California Institute of Technology [producer] http://cces.gov.harvard.edu.

Ansolabehere, S., 2011. Cooperative congressional eletion study, 2011: Common content. [Computer File] Release 1: June 20, 2013. Cambridge, MA: Harvard University [producer] http://cces.gov.harvard.edu.

Ansolabehere, S.D., 2012. Guide to the 2010 cooperative congressional election survey. Available at http://hdl.handle.net/1902.1/17705.

Ansolabehere, S.D., Meredith, M., Snowberg, E., 2013. Asking about numbers: Why and how. Political Analysis, 21, 48-69.

Ansolabehere, S.D., Meredith, M., Snowberg, E., 2014. Mecro-economic voting: Local information and micro-perceptions of the macro-economy. Economics \& Politics, 26, 380-410.

Ansolabehere, S.D., Rivers, D., 2013. Cooperative survey research. Annual Review of Political Science, 16, 307-329.

Barber, B.M., Odean, T., 2001. Boys will be boys: Gender, overconfidence, and common stock investment. Quarterly Journal of Economics, 116, 261-292.

Berinsky, A.J., Huber, G.A., Lenz, G.S., 2012. Evaluating online labor markets for experimental research: Amazon.com's mechanical turk. Political Analysis, 20, 351-368.

Foley, P.W., 2013. Four Essays on the Empirical Analysis of Political Ideology. Ph.D. dissertation. California Institute of Technology, Pasadena, California.

Ghitza, Y., Gelman, A., 2014. The great society, reagan's revolution, and generations of presidential voting. Columbia University, mimeo.

Green, D.P., 1988. On the dimensionality of public sentiment toward partisan and ideological groups. American Journal of Political Science, 32, 758-780.

Hausman, J., 2001. Mismeasured variables in econometric analysis: Problems from the right and problems from the left. Journal of Economic Perspectives, 15, 57-67.

Jost, J.T., Glaser, J., Kruglanski, A.W., Sulloway, F.J., 2003. Political conservatism as motivated social cognition. Psychological Bulletin, 129, 339-375.

Levy, G., Razin, R., 2015. Correlation neglect, voting behavior and polarization. American Economic Review, 105, 1634-1645. 
Meredith, M., 2009. Persistence in political participation. Quarterly Journal of Political Science, 4, 186-208.

Moore, D.A., Healy, P.J., 2007. The trouble with overconfidence. Carnegie Mellon University, mimeo.

Moore, D.A., Healy, P.J., 2008. The trouble with overconfidence. Psychological Review, 115, $502-517$.

Mullainathan, S., Washington, E., 2009. Sticking with your vote: Cognitive dissonance and political attitudes. American Economic Journal: Applied Economics, 1, 86-111.

Ortoleva, P., Snowberg, E., 2013. Overconfidence in political behavior. NBER Working paper no. 19250, National Bureau of Economic Research, Cambridge, MA.

Ortoleva, P., Snowberg, E., 2015. Overconfidence in political behavior. American Economic Review, 105, 504-535.

Oxley, D.R., Smith, K.B., Alford, J.R., Hibbing, M.V., Miller, J.L., Scalora, M., Hatemi, P.K., Hibbing, J.R., 2008. Political attitudes vary with physiological traits. Science, 321, 1667-1670. 